\title{
Effect of phosphate/fluoride electrolytes on mass and dimensional stability of anodization bath manufactured by FDM
}

\author{
Gabriela Strnad ${ }^{1, *}$, Razvan Cazacu ${ }^{1}$, Paul Chetan ${ }^{1}$, Andrei Serban Gaz Florea ${ }^{2}$, and \\ Ferencz Peti $^{3}$ \\ 1 "Petru Maior" University of Tirgu Mures, Faculty of Engineering, Department of Industrial \\ Engineering and Management, Nicolae Iorga 1, Tirgu Mures, Romania \\ ${ }^{2}$ University of Medicine and Pharmacy of Tîrgu Mureş, Faculty of Pharmacy, Department of \\ Fundamental Pharmaceutical Science, Organic Chemistry, Gh. Marinescu 38, Tirgu Mures, Romania \\ ${ }^{3}$ CIE Matricon, Department of Quality, Gh. Doja 155, Tirgu Mures, Romania
}

\begin{abstract}
Present paper is an experimental study on mass and dimensional stability of components manufactured by additive technology of Fused Deposition Modeling (FDM) from PLA and ABS filaments, components to be subjected to the action of aqueous phosphate/fluoride solutions during the process of surface modification and $\mathrm{TiO}_{2}$ nanotubes development on the surface of titanium based materials by electrochemical anodization. Several specimens were printed with $30 \%$ and $100 \%$ fill density; we used control samples of PP, PLA and ABS in order to compare the results. The specimens and control samples were in contact with $1 \mathrm{M}$ $\mathrm{H}_{3} \mathrm{PO}_{4}+0.5 \mathrm{wt} \% \mathrm{HF}$ electrolyte, for 2 hours and 48 hours. Regarding mass stability we found that the specimens' mass is increasing after exposure to electrolyte, showing absorption on to the material, the mass gain being up to $0.2 \%$ from initial mass. Dimensional stability is also questionable; there are modifications of up to $0.05 \mathrm{~mm}$ after 48 hours exposure to electrolyte. All of our results lead to the conclusion that, even if FDM has certain advantages in terms of flexibility of design and short design to product time, drawbacks appear in terms of mass and dimensional stability when the printed components work in aqueous acid solutions, raising questions regarding their safe utilization over time.
\end{abstract}

\section{Introduction}

Additive manufacturing is becoming nowadays more and more relevant for products where customization is of most importance. The advantages that additive manufacturing brings in terms of: flexibility, complexity and variety of the parts, little lead time, little skill manufacturing, few constrains, less waste, no assembly operations required, boost its applications on almost every market (automotive, aerospace, medical, robotics).

${ }^{*}$ Corresponding author: gabriela.strnad@ing.upm.ro 
Fused Deposition Modeling (FDM) works with thermoplastic resins, in form of filaments; the material is heated and extruded out of a small nozzle and the model/part is built-up layer by layer by the deposition of the extruded material which rapidly cools down and solidifies. FDM is one of the quickest additive manufacturing technologies and a large number of materials for plastic filaments are available on the market: polylactic acid (PLA), acrilonitrile butadiene styrene (ABS), polycarbonate (PC), polyamide (PA), polystyrene(PS), polyether ether ketone (PEEK). PLA filament is made from organic and renewable sources; it is safe and easy to print. The material presents good tensile strength, allows 3D printing at high print speeds with good surface quality of printed parts. ABS provides excellent mechanical properties, enhanced interlayer adhesion, minimal warping and reliable bed adhesion.

Taking into account the FDM advantages we planned to use it for the manufacturing of the bath (tank) that we use in our custom-built electrochemical anodization cell. In this laboratory installation, we perform the surface modification of titanium based alloys in order to develop nanostructured oxide layers. Self-ordered nanotubular $\mathrm{TiO}_{2}$ layers attracted lately tremendous research efforts due to their outstanding applications in medicine (implants, stents, valves, and drug delivery systems), solar cells, batteries for electric vehicles, catalyst for fuel cells, and oil-water filtration.

Currently we are able to develop uniform, self-arranged nanotubular $\mathrm{TiO}_{2}$ layers on the surface of pure titanium and Ti6Al4V alloy, by using electrochemical anodization in phosphate/fluoride solutions (Fig. 1). Depending on the process parameters we can develop nanotubes of diameter in 30-120 $\mathrm{nm}$ range and thickness in 100-500 $\mathrm{nm}$ range.
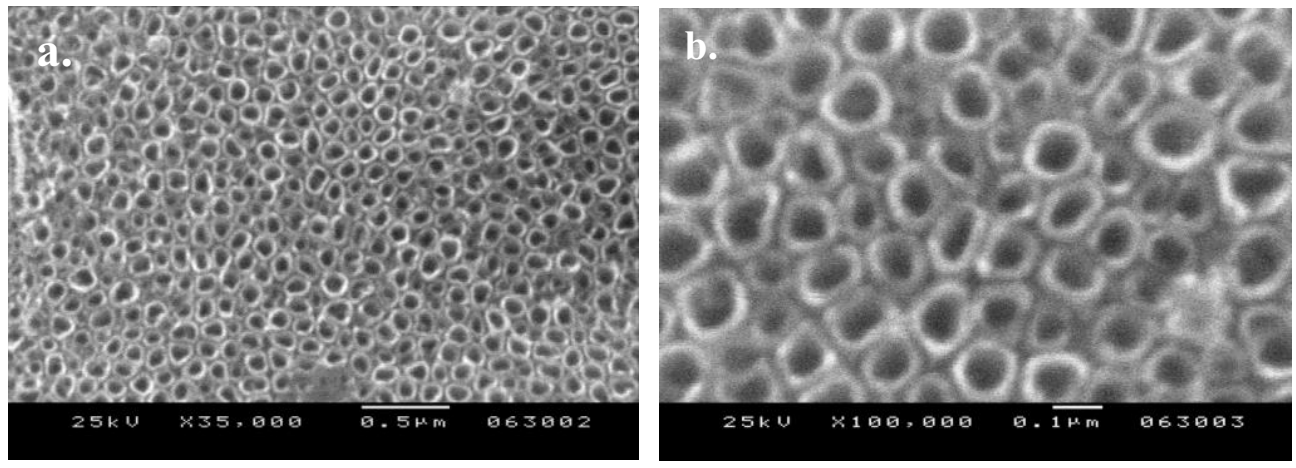

Fig. 1. SEM micrographs of Ti6Al4V surface, anodized in $1 \mathrm{M} \mathrm{H}_{3} \mathrm{PO}_{4}+0.5 \mathrm{wt} \% \mathrm{HF}$, at $\mathrm{U}=20 \mathrm{~V}, 2$ hours, showing the development of well defined, highly ordered nanostructured oxide layer (a 35000X magnification; $b-100000 \mathrm{X}$ magnification) [1].

Our research is focused on applications of these layers in biomedical implants. This is due to the fact that recent results demonstrate that surface modification at nano scale level, by producing an ordered nanostructured surface, promotes enhanced osseointegration process [2-7]. Electrochemical anodization technology can control the morphology, structure and chemical composition of $\mathrm{TiO}_{2}$ layers, leading to enhancement of the surface properties. By optimizing the process parameters of anodization, highly order and self arranged nanostructured surfaces can be developed [8-11]. Our recent results [1, 12-14] are in line with state of the art in this research field, and we bring also new contributions by being able to superimpose nanotubular layers over micro rough topographies [15].

In this context, the aim of present experimental research is to find if the manufacturing of our electrochemical anodization baths by FDM, in order to benefit from this technology advantages, is a good option when the application is related to the usage of $3 \mathrm{D}$ printed components in contact with aqueous acid solutions. There is no available data on filament materials mass and dimensional stability. Moreover, there is no data on stability of FDM 
printed components as their properties depend on the many process parameters (nozzle diameter, nozzle temperature, layer height, shell thickness, print speed, fill density, outer shell speed, inner shell speed, infill speed, etc.) that can be set at different values.

\section{Materials and methods}

The specimens designed for the experimental study performed by us were manufactured by additive technology of Fused Deposition Modeling (FDM) using an Ultimaker 2 Extended $+3 \mathrm{D}$ printing machine.

We printed several baths (specimens 1-4) using PLA (polylactic acid) and ABS (acrylonitrile butadiene styrene) filaments, materials whose main properties are listed in Table 1. (filaments are of original Ultimaker brand).

Table 1. Main properties of filaments used for specimens manufacturing by FDM.

\begin{tabular}{|l|c|c|}
\hline & PLA filament & ABS filament \\
\hline Diameter $[\mathrm{mm}]$ & $2.85 \pm 0.1$ & $2.85 \pm 0.1$ \\
\hline Max. roundness deviation $[\mathrm{mm}]$ & 0.1 & 0.1 \\
\hline Density $\left[\mathrm{g} / \mathrm{cm}^{3}\right.$ ] & 1.24 & 1.10 \\
\hline Melting temperature $\left[{ }^{\circ} \mathrm{C}\right]$ & $145-160$ & $225-245$ \\
\hline Glass transition $\left[{ }^{\circ} \mathrm{C}\right]$ & $\sim 60$ & - \\
\hline Melt mass flow rate $[\mathrm{g} / \mathrm{min}]$ & 0.609 & 0.410 \\
\hline Tensile modulus $[\mathrm{MPa}]$ & 2346.5 & 3681.5 \\
\hline Tensile stress at yield $[\mathrm{MPa}]$ & 49.5 & 33.9 \\
\hline Tensile stress at break $[\mathrm{MPa}]$ & 45.6 & 3.5 \\
\hline Elongation at yield $[\%]$ & 3.3 & 4.8 \\
\hline Elongation at break $[\%]$ & 3.2 & 70.5 \\
\hline Flexural strength $[\mathrm{MPa}]$ & 103 & 2070 \\
\hline Flexural modulus $[\mathrm{MPa}]$ & 3150 & 76 \\
\hline Hardness [Shore D] & 83 & insoluble \\
\hline Water solubility & insoluble & strong oxidizing agents \\
\hline Incompatible materials & oxidizing agents, strong bases & chemically stable \\
\hline Chemical stability & chemically stable & no data available \\
\hline Stability (reactivity) & no data available & \\
\hline
\end{tabular}

The specimen's design was made in CATIA V5, the .stl file was saved and imported in Cura 15.01 software. The parameters used for .gcode generation of our specimens are listed in Table 2. Basically, we used the same parameters, except fill density; from each material we print two specimens: one with hollow interior (infill 30\%) and one with massive interior (infill 100\%).

Chemical solution of $1 \mathrm{M} \mathrm{H}_{3} \mathrm{PO}_{4}+0.5 \mathrm{wt} \% \mathrm{HF}$ was prepared from reagent grade chemicals (Chemical Company) and deionized water. Experiments were carried out at room temperature.

After the specimens were manufactured we subjected them to the following experimental procedure:

1. the initial mass and initial specific dimensions of the specimens were measured; 
2. the chemical solution was put in the interior space of the specimens and maintained there for a duration of 2 hours;

3. after 2 hours the chemical solution was evacuated, the specimens were cleaned by washing in distilled water, carefully wiped, dried in air, and their mass was measured at 1 , and 16 hours after extraction from solution;

4. after 16 hours the selected dimensions of the specimens were measured again;

5. the above-mentioned procedure was repeated in the same way, but with a maintaining duration of 48 hours of chemical solution inside the specimens.

Table 2. Main parameters used for .gcode generation in Cura 15.01 .

\begin{tabular}{|l|c|c|c|c|}
\hline & $\begin{array}{c}\text { Specimen 1 } \\
\text { S1 - PLA 30 }\end{array}$ & $\begin{array}{c}\text { Specimen 2 } \\
\text { S2 - PLA 100 }\end{array}$ & $\begin{array}{c}\text { Specimen 3 } \\
\text { S3 - ABS 30 }\end{array}$ & $\begin{array}{c}\text { Specimen 4 } \\
\text { S4- ABS 100 }\end{array}$ \\
\hline Nozzle size [mm] & 0.4 & 0.4 & 0.4 & 0.4 \\
\hline Layer height [mm] & 0.15 & 0.15 & 0.15 & 0.15 \\
\hline Shell thickness [mm] & 0.8 & 0.8 & 0.8 & 0.8 \\
\hline Print speed [mm/s] & 50 & 50 & 50 & 50 \\
\hline Fill density [\%] & 30 & 100 & 30 & 100 \\
\hline Outer shell speed [mm/s] & 40 & 40 & 40 & 40 \\
\hline Inner shell speed [mm/s] & 80 & 80 & 80 & 80 \\
\hline Infill speed [mm/s] & 100 & 100 & 100 & 100 \\
\hline
\end{tabular}

The weighting of the specimens was measured using Adam AEA-100G analytical balance with an accuracy of $\pm 0.1 \mathrm{mg}$.

Dimensional control was performed on a Zeiss Contura G2 coordinate measuring machine (CMM) equipped with VAST XXT scanning sensor, a Renishaw stylus with a ball radius of $2 \mathrm{~mm}$, scanning error of $\pm 2.5 \mu \mathrm{m}$. A measuring program was designed accordingly to the specific dimensions that were planned to be inspected and whose variations we aim to evaluate.

In order to be able to analyze our results on mass stability we subjected 3 control specimens to the same experimental procedure. The control specimens were: CS - PP (a bath made from polypropylene by injection), CS - PLA (a specimen cut from PLA filament used for FDM), and CS - ABS (a specimen cut from ABS filament used for FDM). CS PLA and CS - ABS were subjected to the electrolyte action by immersing them in the chemical solution.

\section{Results and discussion}

The specimens were designed in order to allow us to conclude on mass stability of materials after exposure in aqueous chemical solutions, and also on the stability of specific features' dimensions. These features are in direct link with the final design of our electrochemical anodization bath where we perform our experiments in order to modify, at nanoscale level, the surface of titanium based alloys for biomedical implants.

Fig. 2 presents the isometric drawing of the specimens and the specific dimensions of interest for present research work.

In Fig. 3.a the specimen's model loaded in Cura software for the generation of the .gcodes for $3 \mathrm{D}$ printing is presented. We generate four different .gcodes using different settings for: material (PLA, ABS) and fill density (30\%, 100\%). Printing time was $\sim 1 \mathrm{~h} 10$ min for the specimens with $30 \%$ infill and $\sim 3$ h 20 min for the specimens with $100 \%$ infill. 
Fig. 3.b presents an image taken during one specimen's measuring process on Zeiss Contura G2 CMM.
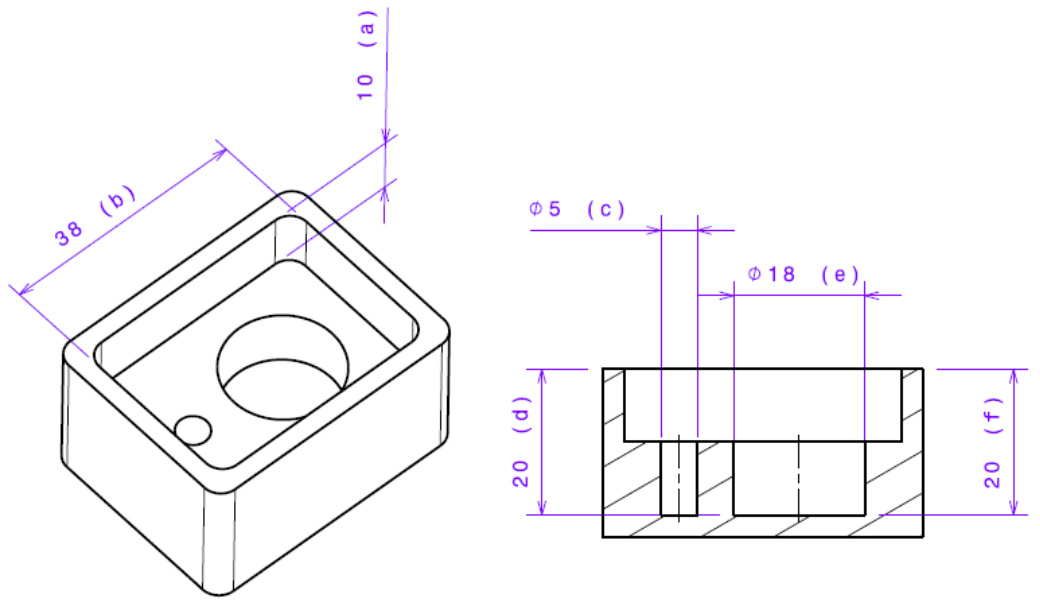

Fig. 2. The specimen's drawing and indication of nominal dimensions that were measured.
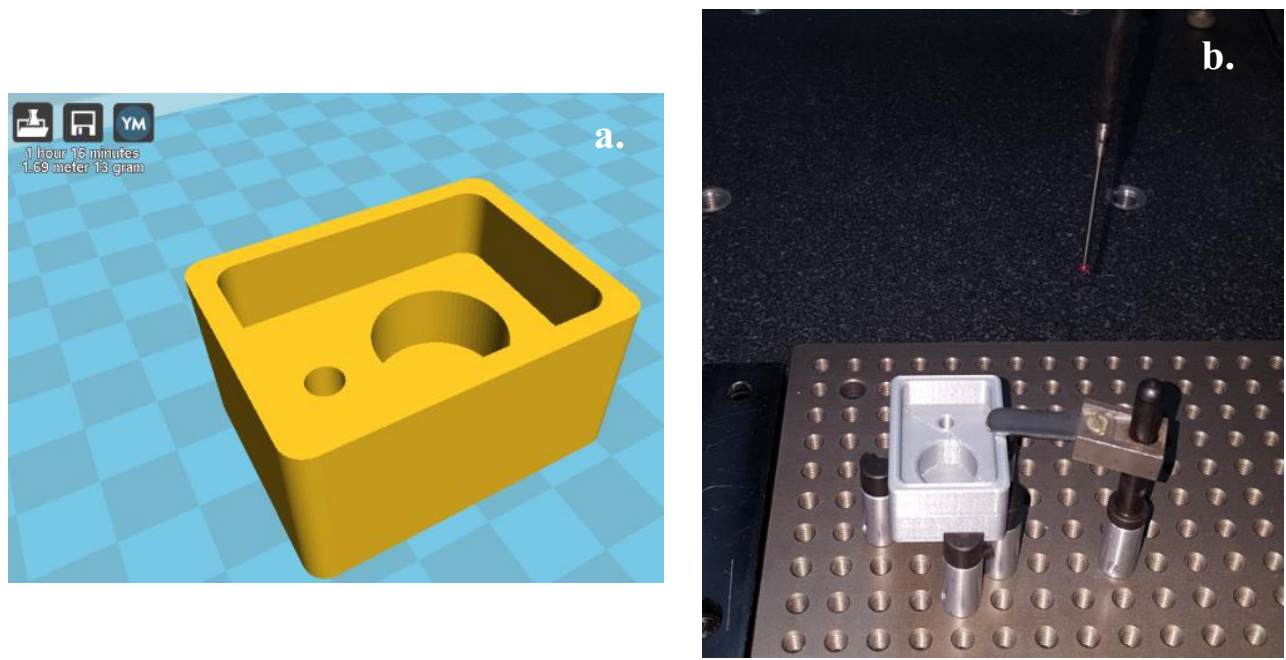

Fig. 3. The specimen's model loaded in Cura 15.01 software (a); Dimensional control on CMM (b).

Tables 3 and 4 summarize the results of our experiments on the influence of the electrolyte on mass stability. By analyzing the results, we can affirm that there is a non negligible influence of chemical solution on specimens mass.

After 2 hours of exposure (Table 3) to the aqueous acid based solution the mass of control samples does not suffer any changes (after complete drying, which occurs in a time shorter than 1 hour for PP and ABS filament), but the mass of FDM manufactured specimens is changing, demonstrating that the surfaces in contact with chemical electrolyte absorb it (Table 3). This is due to the inherent porosity of the surfaces resulting from layer by layer deposition during FDM process. It is interesting to observe that in the case of PLA the difference in mass is bigger in the case of specimen printed with $100 \%$ infill compared with the one printed with $30 \%$ infill $(0.12 \%$ compared with $0.08 \%)$. In the case of ABS the situation is opposite, the specimen printed with $100 \%$ fill density exhibit a lower mass 
difference, this sample having the lowest electrolyte action influence $(0.02 \%$ from its initial mass).

Table 3. The results on the influence of 2 hours exposure to the action of phosphate/fluoride electrolyte on specimens and control samples mass.

\begin{tabular}{|c|c|c|c|c|c|c|c|}
\hline \multirow[t]{3}{*}{ Specimen } & \multirow{3}{*}{$\begin{array}{c}\text { Initial } \\
\text { mass } \\
\mathbf{M}_{1}[g]\end{array}$} & \multicolumn{2}{|c|}{$\begin{array}{l}\text { Mass after } 2 \mathrm{~h} \text { in } \\
\text { electrolyte } \mathrm{M}_{2}[\mathrm{~g}]\end{array}$} & \multicolumn{4}{|c|}{$\begin{array}{c}\text { Difference in mass after } 2 \mathrm{~h} \text { in } \\
\text { electrolyte } \Delta M=M_{2}-M_{1}\end{array}$} \\
\hline & & \multirow{2}{*}{$\begin{array}{l}1 \mathrm{~h} \text { of } \\
\text { drying }\end{array}$} & \multirow{2}{*}{$\begin{array}{l}16 \mathrm{~h} \text { of } \\
\text { drying }\end{array}$} & \multicolumn{2}{|c|}{$1 \mathrm{~h}$ of drying } & \multicolumn{2}{|c|}{$16 \mathrm{~h}$ of drying } \\
\hline & & & & {$[\mathrm{mg}]$} & $\%$ & {$[\mathrm{mg}]$} & $\%$ \\
\hline S1 - PLA 30 & 14.1244 & 14.1431 & 14.1357 & 18.7 & 0.13 & 11.3 & 0.08 \\
\hline S2 - PLA 100 & 24.4316 & 24.4748 & 24.4605 & 43.2 & 0.18 & 28.9 & 0.12 \\
\hline S3 - ABS 30 & 14.3764 & 14.3988 & 14.3970 & 22.4 & 0.16 & 20.6 & 0.14 \\
\hline S4 - ABS 100 & 23.2452 & 23.2476 & 23.2495 & 2.4 & 0.01 & 4.3 & 0.02 \\
\hline CS - PP & 6.6384 & 6.6384 & 6.6384 & 0.0 & 0.00 & 0.0 & 0.00 \\
\hline CS - PLA & 0.3424 & 0.3428 & 0.3424 & 0.4 & 0.12 & 0.0 & 0.00 \\
\hline CS - ABS & 0.3336 & 0.3336 & 0.3336 & 0.0 & 0.00 & 0.0 & 0.00 \\
\hline
\end{tabular}

After 48 hours of exposure (Table 4) to the aqueous acid based solution the mass of ABS control sample (measured after 16 hours of drying) is also influenced by the contact with electrolyte. The PLA control sample mass remain unchanged, and the mass of ABS control sample is changing, showing that even extruded filament of ABS absorbs the solution in which it is put. The mass of PP control sample appears to be less the initial one, that can be the results of a slight dissolution of the material ( $0.6 \mathrm{mg}$ mass loss); but the value is very low, is the range of analytical balance accuracy, so we cannot affirm that we are certain that the material dissolution occurred. The mass differences in the case of PLA specimens are bigger than those measured after two hours of exposure $(0.15 \%$ vs. $0.08 \%$ and $0.2 \%$ vs. $0.12 \%$ ), and also the difference is higher in the case of S2 - PLA 100 compared with S1 - PLA $30(0.2 \%$ vs. $0.15 \%)$. In the case of ABS the mass differences are of $0.1 \%$ from initial mass, being lower compared to PLA.

Table 4. The results on the influence of 48 hours exposure to the action of phosphate/fluoride electrolyte on specimens and control samples mass.

\begin{tabular}{|c|c|c|c|c|c|c|c|}
\hline \multirow[t]{3}{*}{ Specimen } & \multirow{3}{*}{$\begin{array}{c}\text { Initial } \\
{\text { mass } \mathbf{M}_{1}}_{[\mathrm{g}]}\end{array}$} & \multicolumn{2}{|c|}{$\begin{array}{l}\text { Mass after } 48 \mathrm{~h} \text { in } \\
\text { electrolyte } \mathrm{M}_{2}[\mathrm{~g}]\end{array}$} & \multicolumn{4}{|c|}{$\begin{array}{c}\text { Difference in mass after } 48 \mathrm{~h} \text { in } \\
\text { electrolyte } \Delta \mathrm{M}=\mathrm{M}_{2}-\mathrm{M}_{1}\end{array}$} \\
\hline & & \multirow{2}{*}{$\begin{array}{l}1 \mathrm{~h} \text { of } \\
\text { drying }\end{array}$} & \multirow{2}{*}{$\begin{array}{l}16 \mathrm{~h} \text { of } \\
\text { drying }\end{array}$} & \multicolumn{2}{|c|}{$1 \mathrm{~h}$ of drying } & \multicolumn{2}{|c|}{$16 \mathrm{~h}$ of drying } \\
\hline & & & & {$[\mathrm{mg}]$} & $\%$ & {$[\mathrm{mg}]$} & $\%$ \\
\hline S1 - PLA 30 & 14.1357 & 14.1852 & 14.1567 & 49.5 & 0.35 & 21.0 & 0.15 \\
\hline S2 - PLA 100 & 24.4605 & 24.5801 & 24.5083 & 119.6 & 0.49 & 47.8 & 0.20 \\
\hline S3 - ABS 30 & 14.3970 & 14.4161 & 14.4116 & 19.1 & 0.13 & 14.6 & 0.10 \\
\hline S4 - ABS 100 & 23.2495 & 23.2735 & 23.2727 & 24.0 & 0.10 & 23.2 & 0.10 \\
\hline CS - PP & 6.6384 & 6.6380 & 6.6378 & -0.4 & -0.01 & -0.6 & -0.01 \\
\hline CS - PLA & 0.3428 & 0.3438 & 0.3428 & 1.0 & 0.29 & 0 & 0.00 \\
\hline CS - ABS & 0.3336 & 0.3344 & 0.3340 & 0.8 & 0.24 & 0.4 & 0.12 \\
\hline
\end{tabular}

As a general observation, we can affirm that there is a certain influence of aqueous $1 \mathrm{M}$ $\mathrm{H}_{3} \mathrm{PO}_{4}+0.5 \mathrm{wt} \% \mathrm{HF}$ electrolyte on mass stability of FDM manufactured parts. The chemical solution is absorbed onto the surface of the specimens, these raising questions of the surface contamination and further possibility of cleaning. This detrimental influence does not exist in the case of control sample manufactured by injection. 
As regards dimensional stability under the influence of electrolyte, Table 5 presents the results of our CMM investigation of specific dimensions on each specimen.

Table 5. The results on the influence of exposure to the action of phosphate/fluoride electrolyte on specimens' dimensional stability.

\begin{tabular}{|c|c|c|c|c|c|c|}
\hline & $\begin{array}{c}\text { Nominal } \\
\text { dimension } \\
\text { dN }_{\mathrm{N}}[\mathrm{mm}]\end{array}$ & $\begin{array}{c}\text { Initial } \\
\text { dimension } \\
\text { di } 1_{1}[\mathrm{~mm}]\end{array}$ & $\begin{array}{c}\text { Dimension } \\
\text { after } 2 \mathrm{~h} \text { in } \\
\text { electrolyte } \\
\mathrm{d}_{2}[\mathrm{~mm}]\end{array}$ & $\begin{array}{l}\text { Dimension } \\
\text { after } 48 \mathrm{~h} \text { in } \\
\text { electrolyte } \\
\mathrm{d}_{3}[\mathrm{~mm}]\end{array}$ & $\begin{array}{c}\text { Difference } \\
\text { after } 2 h \text { in } \\
\text { electrolyte } \\
\Delta \mathrm{d}=\mathrm{d}_{2}-\mathrm{d}_{1} \\
{[\mu \mathrm{m}]}\end{array}$ & $\begin{array}{c}\text { Difference } \\
\text { after } 48 \text { h in } \\
\text { electrolyte } \\
\Delta \mathrm{d}=\mathrm{d}_{3}-\mathrm{d}_{1} \\
{[\mu \mathrm{m}]}\end{array}$ \\
\hline \multirow{6}{*}{ 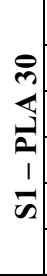 } & 10 (a) & 9.931 & 9.943 & 9.948 & 12 & 17 \\
\hline & 38 (b) & 37.885 & 37.893 & 37.909 & 8 & 24 \\
\hline & $\varnothing 5$ (c) & 4.798 & 4.799 & 4.800 & 1 & 2 \\
\hline & $20(d)$ & 19.880 & 19.885 & 19.894 & 5 & 14 \\
\hline & $\varnothing 18(\mathrm{e})$ & 17.725 & 17.728 & 17.734 & 3 & 9 \\
\hline & $20(\mathrm{f})$ & 19.901 & 19.916 & 19.926 & 15 & 25 \\
\hline \multirow{6}{*}{ 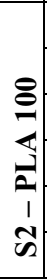 } & 10 (a) & 9.891 & 9.889 & 9.896 & -2 & 5 \\
\hline & 38 (b) & 37.953 & 37.967 & 37.983 & 14 & 30 \\
\hline & $\varnothing 5$ (c) & 4.892 & 4.893 & 4.894 & 1 & 2 \\
\hline & $20(d)$ & 19.895 & 19.906 & 19.917 & 11 & 22 \\
\hline & $\varnothing 18(\mathrm{e})$ & 17.818 & 17.823 & 17.829 & 5 & 11 \\
\hline & 20 (f) & 19.898 & 19.905 & 19.921 & 7 & 23 \\
\hline \multirow{6}{*}{ 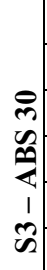 } & 10 (a) & 9.781 & 9.786 & 9.829 & 5 & 48 \\
\hline & 38 (b) & 37.680 & 37.671 & 37.677 & -9 & -3 \\
\hline & $\varnothing 5$ (c) & 4.604 & 4.603 & 4.604 & -1 & 0 \\
\hline & 20 (d) & 19.859 & 19.866 & 19.863 & 7 & 4 \\
\hline & $\varnothing 18(\mathrm{e})$ & 17.484 & 17.483 & 17.487 & -1 & 3 \\
\hline & $20(\mathrm{f})$ & 19.797 & 19.794 & 19.825 & -3 & 28 \\
\hline \multirow{6}{*}{ 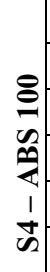 } & 10 (a) & 9.787 & 9.781 & 9.770 & -6 & -17 \\
\hline & 38 (b) & 37.800 & 37.795 & 37.795 & -5 & -5 \\
\hline & $\varnothing 5$ (c) & 4.534 & 4.533 & 4.532 & -1 & -2 \\
\hline & $20(d)$ & 19.628 & 19.595 & 19.576 & -33 & -52 \\
\hline & $\varnothing 18(\mathrm{e})$ & 17.431 & 17.429 & 17.428 & -2 & -3 \\
\hline & $20(\mathrm{f})$ & 19.497 & 19.487 & 19.469 & -10 & -28 \\
\hline
\end{tabular}

Analyzing the results, a first discussion can be made on the dimensional accuracy of printed specimens. All dimensions on the manufactured specimens are smaller than the prescribed ones, the deviations from nominal dimensions being in the range: $0.069-0.275$ $\mathrm{mm}$ for S1- PLA 30, $0.047-0.182 \mathrm{~mm}$ for S2 - PLA 100, $0.141-0.516 \mathrm{~mm}$ for S3- ABS 30 , and $0.200-0.569$ for S4 - ABS 100. Deviations of such values show a poor dimensional accuracy of FDM process.

Regarding the influence of electrolyte on specific dimensions of the specimens our results show that there are notable changes even after a short exposure of 2 hours. The PLA specimens show a slight increase in dimensions, while ABS specimens show mainly a decrease in dimensions. This shows that ABS is swelling in aqueous acid solution. The measured difference from initial dimensions can be as big as $0.033 \mathrm{~mm}$. At long exposure duration of 48 hours, PLA show also high modifications of initial dimensions of up to $0.030 \mathrm{~mm}$, which can suggest a dissolution process. It is interesting that $\mathrm{S} 3-\mathrm{ABS} 30$ show 
an increase in dimensions, which compared with the decrease of them at 2 hours of exposure, seems to indicate that in the same time the swelling and dissolution occurs, and for long exposure time the dissolution effect is higher than the swelling one. For S4 -ABS 100 all dimensions are lower than initial ones, showing a predominant swelling effect, the differences are up to $0.052 \mathrm{~mm}$.

This dimensional instability in chemical electrolyte, together with the initial poor manufacturing accuracy leads us to the conclusion that FDM is not a suitable solution for manufacturing of parts that will be in contact with acid based phosphate/fluoride electrolytes. Furthermore, our results show an increase in all specimens mass, showing absorption of chemical solutions, raising questions regarding their safe utilization.

\section{Conclusions}

As the manufacturing of the mechanical components by using additive technology brings important advantages in terms of flexibility of design and short design to product time, present research aimed to study the opportunity of manufacture, by FDM process, of specific component of an electrochemical anodization set-up, which is anodization bath.

Using PLA and ABS we printed 4 specimens (30\% and 100\% fill density) and subjected them to the action of $1 \mathrm{M} \mathrm{H}_{3} \mathrm{PO}_{4}+0.5 \mathrm{wt} \% \mathrm{HF}$ electrolyte (for duration of 2 hours and 48 hours). This specific acid mixture is the aqueous solution that allows the development of titania nanotubes on titanium based materials, by using electrochemical anodization. We aimed to study the mass and dimensional stability of these specimens, in the absence of detailed information on this issue, and in conditions in which the filaments technical specifications are that the materials are chemical stable, but the specifications on stability are of "no data available".

Our results on mass stability show an increase of it after exposure to chemical solution, in the range of $0.01 \%$ from initial mass to $0.5 \%$ from initial mass. After 48 hours of exposure and 16 hours of drying the specimens still present a mass gain of $0.1 \%-0.2 \%$, raising serious questions regarding the surface contamination and further possibility of cleaning. The control sample made from PP by injection does not show this absorption effect.

Our results on dimensional stability show a poor initial manufacturing accuracy of FDM process, followed by changes in specimens' dimensions as a result of exposure to chemical solution. The modification of dimensions depends on material and infill density. On PLA (regardless of infill) the dimensions are increasing at short and long exposure time, showing a slight dissolution effect, being up to $0.030 \mathrm{~mm}$. ABS exhibits a decrease in dimensions, showing a swelling effect, except the case of the specimen with $30 \%$ infill exposed for 48 hours to electrolyte, which have bigger dimensions that initial ones, showing that dissolution effect is stronger than swelling one. The modification of ABS specimens' dimensions is up to $0.052 \mathrm{~mm}$.

To sum up, our results lead us to the conclusion that FDM is not a suitable solution for manufacturing of parts that will be in contact with acid based phosphate/fluoride electrolytes. Even it is a flexible and rapid method to deliver finished product, in the specific application studied by us, which can be extended to other applications that deal with aqueous solutions or chemical mixtures, the drawbacks that appear in terms of mass and dimensions stability have to be taken in account.

This work was supported by a grant of the Romanian National Authority for Scientific Research and Innovation, CNCS/CCCDI-UEFISCDI, project number PN-III-P2-2.1-PED-2016-0142, within PNCDI III. 


\section{References}

1. G. Strnad, C. Petrovan, O. Russu, L. Jakab-Farkas, IoP Conf. Series: Materials Science and Engineering, 161 doi: 10.1088/1757-899X/161/1/012051 (2016)

2. K. Gulati, S. Maher, D. M. Findlay, D. Losic, Nanomedicine, 11 (14), 1847-1864 (2016)

3. D. Karazisis, A. M. Ballo, S. Petronis, H. Agheli, L. Emanuelsson, P. Thomsen, O. Omar, Int J of Nanomed, 11, 1367-1381 (2016)

4. A. Mazare, Corrosion Science, 103, 215-222 (2016)

5. M. Kulkarni, A. Mazare, E. Gongadze, S. Perutkova, V. Kralj-Iglič, I. Milosev, P. Schmuki, A. Iglic, M. Mozetic, Nanotechnology, 26, 062002 (2015)

6. K. Narendrakumar, M. Kulkarni, O. Addison, A. Mazare, I. Junkar, P. Schmuki, R. Sammons, A. Iglic, Dental Materials, 31, 1460-1468 (2015)

7. E. Beltrán-Partida, A. Moreno-Ulloa, B. Valdez-Salas, C. Velasquillo., M. Carrillo, A. Escamilla, E. Valdez, F. Villarreal, Materials, 8, 867-88 (2015)

8. M. Kulkarni, et al., Advanced Material Letters, 7 (1), 23-28 (2016)

9. K. Gulati, A. Santos, D. Findlay, D. Losic, Journal of Physical Chemistry C, 119, 16033-16045 (2015)

10. A. Mazare, et al, Surf. Interface Anal., 46, 186-192 (2014)

11. K. Lee, et al., Chemical Reviews, 114, 9385-9454 (2014)

12. G. Strnad, L. Jakab-Farkas, D. Portan, Academic Journal of Manufacturing Technology, 14 (4), 112-118 (2016)

13. G. Strnad, L. Jakab-Farkas, C. Petrovan, O. Russu, Procedia Engineering, 181, 242248 (2017)

14. G. Strnad, Z. German-Sallo, L. Jakab-Farkas, C. Petrovan, D. Portan, MATEC Web of Conferences 112, 04021 (2017)

15. G. Strnad, D. Portan, L. Jakab-Farkas, C. Petrovan, O. Russu, Materials Science Forum, 907, 91-98 (2017) 
